\title{
Economics
}

\section{Asymmetry of Long-Short Cost in Derivatives Market, Heterogeneous Beliefs and Stock Price Crash: A Theoretical Model}

\author{
Yiming $\mathrm{Ma}^{1}$, Juncheng $\mathrm{Li}^{2}$, Yaguang $\mathrm{Li}^{3}, \mathrm{Ke} \mathrm{Gao}^{3,4}$ \\ ${ }^{1}$ Chinese Academy of Finance and Development, Central University of Finance and Economics, Beijing, P. R. China \\ ${ }^{2}$ School of Finance, Central University of Finance and Economics, Beijing, P. R. China \\ ${ }^{3}$ School of Econmics and Management, Shandong Youth University of Political Scienece, Jinan, P. R. China \\ ${ }^{4}$ Development Research Center of Shandong Provincial People's Government, Jinan, P. R. China
}

Email address:

18511693068@163.com(Yiming Ma),2779583526@qq.com(Juncheng Li), liyaguang@163.com(YaguangLi),gkfly@126.com(Ke Gao)

\section{To cite this article:}

Yiming Ma, Juncheng Li, Yaguang Li, Ke Gao. Asymmetry of Long-short Cost in Derivatives Market, Heterogeneous Beliefs and Stock Price Crash: A Theoretical Model. Economics. Vol. 8, No. 2, 2019, pp. 73-87. doi: 10.11648/j.eco.20190802.15

Received: May 17, 2019; Accepted: July 23, 2019; Published: July 29, 2019

\begin{abstract}
In this paper, we construct a four-period-double-market model in this paper. By including the stock market with short selling restrictions and the derivative market without short selling restrictions but with long-short costs in the model, we study the relationship between the asymmetry of long-short cost in derivative market, investors' heterogeneous beliefs and the stock price crash risk. According to the conclusion of closed solution of our model, the asymmetry of short cost in derivatives market will distort the implied price of derivatives market, which will send a wrong message to stock market and intertwined with investors' heterogeneous beliefs in the stock market. Moreover, under the general equilibrium model, a derivative market with symmetrical long-short cost can completely eliminate the risk of stock price crash. But if the short-selling cost is relative higher than the buying cost, the stock price will be overvalued in the early periods, and the negative events will result in a more serious stock price crash than the single market situation. Our model emphasizes the distorting effect of long-short cost asymmetry on the price discovery and information flow function of derivatives market, and reminds government departments to improve market mechanism and strengthen supervision when promoting the development of derivatives market. The government should actively guide the derivatives market to play its due role in the financial market.
\end{abstract}

Keywords: Heterogeneous Beliefs, Stock Price Crash, Asymmetric Long-Short Costs

\section{Introduction}

Research on the causes of stock price collapse has been quite rich. On the one hand, researchers show that the basic characters of enterprises can lead to the increase of the stock crash risk [1-5], management's characteristics and behavior are also one of the main culprits of stock price crash [6-11]. On the other hand, from the perspective of imperfection of the market, researchers demonstrate the short-selling restrictions in the stock market [12-15] and the defects of derivatives market $[16,17]$ will also increase the stock crash risk. However, these studies are mainly from the perspective of empirical research. There are still few theoretical models on the causes of stock price crash.
A landmark work on the theory of stock price collapse is Hong and Stein (2003) [13]. In this paper, they use a four-period single market model to prove that when there is short-selling restriction in the market, the incomplete, delayed and asymmetric reaction of investors' heterogeneous beliefs leads to the negative information or emotions of investors being hidden first, and then suddenly erupts when bad news occurs, which directly leads to the occurrence of stock price crash.

With the development of financial derivatives market (such as options, futures, CDS market), their characteristics of high leverage, high liquidity, no short-selling restrictions attracts a large number of investors to participate in, and investors' information will inevitably be reflected in these derivatives markets. Since the biggest difference between derivatives 
market and stock market is that there is no short selling restriction in derivative market, it is very meaningful to consider how investors' heterogeneous beliefs flow in a stock market with short selling restriction and a derivatives market without short selling restriction.

We extend Hong and Stein's (2003) [13] model to a two-market situation. In our model, a stock market with short selling restrictions coexists with a derivative market without short selling restrictions. The cost of long or short stocks in the derivative market will affect the release of investors' information. This information interacts with the information expressed in the stock market, and ultimately, it will have an impact on the stock market crash.

Based on our model, we find that the asymmetry of long-short cost in derivatives market will affect the formation of stock price crash in the final stock market. The existence of short-selling costs distorts the reaction of positive and negative information. Higher short-selling costs are not conducive to the disclosure of negative information and the implied price of derivatives market will be overvalued. This information will lead to excessive price rises in the stock market, so the risk of stock price crashnow is even exceeding that of single market. This phenomenon has been alleviated with the gradual decrease of short-selling costs. In particular, the existence of derivatives market can completely eliminate the risk of stock price collapse when there are symmetrical long-short costs (that is, when the cost of buying is equal to the cost of short selling), in another word, the information is perfectly disclosed at this time and the equilibrium stock price perfectly reflects the heterogeneous beliefs of all investors.

\section{Economic Setup}

\subsection{Basic Setting}

Based on Hong and Stein (2003) [13], the model has 4 dates, which can be label time $0,1,2$ and 3 . There is a stock that will pay a terminal dividend of $\mathrm{D}$ on the stock market at time 3 . Unlike Hong and Stein (2003) [13], which only considers a stock market with short selling constraints, we introduce a derivatives markets to relax the short selling constraints in the stock market. More generally, we consider the transaction costs of longing or shorting a stock in derivatives markets, and we find that the asymmetric trading costs will affect the final stock price and ultimately affect the stock price crash. Last but not least, we assume that there are 3 kinds of investors, including an optimistic investor A, a pessimistic investor B and risk-neutral rational arbitrage investors. The optimistic investor A will get a good signal about the stock dividend, while the pessimistic investor B will get a bad signal about the stock dividend. Both A and B cannot short their stock in the stock market because of the short sell constraint, but they can short or long the stock in the derivative market after they pay the transaction costs. The arbitrageurs can be treated as the market-maker, they have no access to information and the main job of them is to clear the market and set a rational price. As the market-maker, arbitrageurs can short their stock in the stock market and derivatives market without any cost.

\subsection{Information Structure and Investor Demand}

Investor $\mathrm{A}$ and $\mathrm{B}$ take turns getting signals about the terminal dividend. In particular, at time 1 , investor B get $S_{B}$, then investor A will get $S_{A}$ at time 2. We think each investor is equally informative and the terminal dividend is given by

$$
\mathrm{D}=\frac{S_{A}+S_{B}}{2}+\varepsilon, \varepsilon \sim N\left(0, \sigma^{2}\right)
$$

$S_{B}$ is uniformly distributed on the interval $[0,2 \mathrm{~V}]$ and $S_{A}$ is uniformly and independently distributed on the interval $[\mathrm{H}, 2 \mathrm{~V}+\mathrm{H}]$. Thus the rational expectation of $S_{B}$ and $S_{A}$ are $\mathrm{V}$ and $\mathrm{V}+\mathrm{H}$. Here, $\mathrm{H} \in[0,2 \mathrm{~V}]$ is the ex-ante measure of the heterogeneity of opinions. This set up implies that investor $\mathrm{B}$ is more bearish than investor A at the beginning. Also, by restricting the model to the case that $\mathrm{B}$ move first can high-light the central intuition that the bad information may hidden first, and can greatly reduce the complexity of the analysis.

Both investors are assumed to be overconfidence, that is, investors believe their own information even after they have known each other's information. Investors' demand on the stock market in time 1 and time 2, after seeing the stock price $P_{t}$ andin light of the short-sell constraint, are given by follow.

Investor A's demand (get information at time 2):

$Q_{A}^{S, 1}=\left\{\begin{array}{c}V+H-P_{1} \text { if } P_{1}<V+H: \text { buy when price is low } \\ 0 \text { if } P_{1} \geq V+H: \text { can not short sell in stock market }\end{array}\right.$

$$
Q_{A}^{S, 2}=\left\{\begin{array}{c}
S_{A}-P_{2} \text { if } P_{2}<S_{A}: \text { buy when price is low } \\
0 \text { if } P_{2} \geq S_{A}: \text { can not short sell in stock market }
\end{array}\right.
$$

Investor B`s demand (get information at time 1):

$$
Q_{B}^{S, t=1,2}=\left\{\begin{array}{c}
S_{B}-P_{t} \text { if } P_{t}<S_{B}: \text { buy when price is low } \\
0 \text { if } P_{t} \geq S_{B}: \text { can not short sell in stock market }
\end{array}\right.
$$

Also, investors can long or short the stock based derivatives on the derivative market, with no short-sell constraint. More generally, we assume there is a transaction cost in the derivative market. Such transaction cost may come from the entry barriers and the margin system. The existence of transaction costs makes it impossible for us to do long or short perfectly. If investors are trying to long (short) $N$ stocks on the derivative market, they can only long $c_{1} N$ (short $c_{2} N$, $\left.c_{1}, c_{2} \in[0,1]\right)$ stocks at last. Here $1-c_{1}$ and $1-c_{2}$ measure the cost of long and short, respectively. We can derive the investors' implied demand of stock in the derivative market in time 1 and time 2, after seeing the stock price $P_{t}$ and in light of the transaction cost,

Investor A`s demand (get information at time 2):

$$
Q_{A}^{O, 1}=\left\{\begin{array}{c}
c_{1}\left(V+H-P_{1}\right) \text { if } P_{1}<V+H: \text { buy when price is low } \\
c_{2}\left(V+H-P_{1}\right)<0 \text { if } P_{1} \geq V+H \text { : short sell in option market }
\end{array}\right.
$$




$$
Q_{A}^{o, 2}=\left\{\begin{array}{c}
c_{1}\left(S_{A}-P_{2}\right) \text { if } P_{2}<S_{A}: \text { buy when price is low } \\
c_{2}\left(S_{A}-P_{2}\right)<0 \text { if } P_{2} \geq S_{A}: \text { short sell in option market }
\end{array}\right.
$$

Investor B`s demand (get information at time 1):

$$
Q_{B}^{O, t=1,2}=\left\{\begin{array}{c}
c_{1}\left(S_{B}-P_{t}\right) \text { if } P_{t}<S_{B}: \text { buy when price is low } \\
c_{2}\left(S_{B}-P_{t}\right) \text { if } P_{t} \geq S_{B}: \text { short sell in option market }
\end{array}\right.
$$

\subsection{The Price-Setting Mechanism}

At time 0 , no investor gets the information and the initial price will be set as theex-ante expectation of the terminal dividend

$$
P_{0}^{S}=\frac{V+H+V}{2}=V+\frac{H}{2}
$$

As time goes on, more information will be realized and the pricing process become more complicated, we follow the mechanism of Hong and Stein (2003) [13].

This pricing is similar to a down price auction, consider an auctioneer who will charge a trial price $p_{t}$ and any time $\mathrm{t}$ and investors respond by calling out their demand. Because of the short-sell constraint, A and B can only call out something when their demand is positive, while the arbitrageurs are free to call out either positive or negative demands. The arbitrageurs are able to observe any demands called out by A and $\mathrm{B}$ and the market clears when the arbitrageurs' demand are 0 . The auction will lower the price after seeing a negative demand from the arbitrageurs and raises the price when the arbitrageurs`demand is positive. This process continues until the market clears. Then, investor A and B will long or short the stock-based derivatives in the derivative market and the price adjustment process in the derivative market is given by follow.

Given a stock price $P_{S}$ and the signal of investor A and B: $S_{A}$ and $S_{B}$. Generally, we assume $S_{A}>P^{S}>S_{B}$. Thus, investor A will long the stock in the derivative market while investor B will short the stock and the implied stock price on the derivative market is

$$
P^{O}=P^{S}+c_{1}\left(S_{A}-P^{S}\right)+c_{2}\left(S_{B}-P^{S}\right)
$$

Then the arbitrageurs adjust the stock price based on the derivative market, we assume that the final price will be the weighted average of the stock price and the implied stock price on the derivative market

$$
\begin{gathered}
P^{F}=(1-\theta) P^{S}+\theta P^{O}=P^{S}+\theta\left(c_{1}\left(S_{A}-P^{S}\right)+\right. \\
\left.c_{2}\left(S_{B}-P^{S}\right)\right)
\end{gathered}
$$

Here, $\theta$, the weight of the derivative implied price, measures the quality of information transmitted from the derivative market to the stock market and the arbitrageurs' dependence on derivatives market information

Lemma 1. If the bad information $S_{B}$ is hidden at price $P^{S}$ $\left(S_{B} \leq P^{S}\right)$, such information will keep hidden in the stock market after the adjustment of the derivative market.

An intuitive property of the pricing process is that the bad information may not initially appear in the stock market because of the auction process, but with the derivatives market adjustment, the final price may be more reasonable than the single market.

\subsection{A Simple Example}

The following story is a simple example of our model. Consider a stock that will pay a dividend of $\$ 8$ at time 3 . Investor $A$ and $B$ will receive different information at different times. In particular, at time 1 , investor B get $S_{B}$, then investor A will get $S_{A}$ at time 2 . We assume that $S_{B}$ is uniformly distributed on the interval $[0,20]$ and $S_{A}$ is uniformly and independently distributed on the interval $[5,20+5]$, here 5 measures the heterogeneous believe between investor A and B. In other words, this is difference between the optimistic opinion and pessimistic opinion.

At time 0 , the optimistic investor $\mathrm{A}$ and the pessimistic investor B share different expectations for the dividend, $\$ 15$ and $\$ 10$. If the risk-neutral rational arbitrage investors know all the information about $\mathrm{A}$ and $\mathrm{B}$, then the reasonable price given by arbitrageurs is the mean of the expected price of $\mathrm{A}$ and $\mathrm{B}, \$ 12.5$.

At time 1, the pessimistic investor B will get bad news about the terminal dividend, say $\$ 3$, while the optimistic investor A gets no new information, the rational price at this case should be $(\$ 3+\$ 15) / 2=\$ 9$. Now let's first consider the stock market. Investor A will buy the stock as long as the price is less than $\$ 12$, but investor B will keep silence when the price is greater than $\$ 6$ because of the short sell constraint. The arbitrageurs, with no short sell constraint, will clear the market and the equilibrium price is the price when the demand for arbitrageurs is 0 , that is to say, the equilibrium price will be reached when the market price is equal to the expected price of arbitrageurs. For example, when investors face a price of $\$ 12$, investor A will long the stock but investor B will do nothing, thus the arbitrageurs see $A$ 's signal $\$ 15$ and give an expectation of $\mathrm{B}$ 's signal which equal to half the current price $\$ 12 / 2=\$ 6$. And their expected price at this time is $(\$ 6+\$ 15) / 2=\$ 10.5$ which is less than the current price $\$ 12$. The arbitrageurs are willing to long the stock and the stock price will go down. In fact, according to the proof of Lemma 2 (see Appendix), the equilibrium stock price in this case should be $\$ 10$. At this price, A will long the stock and $\mathrm{B}$ won`t do anything, the arbitrageurs 'expectation of B's signal is $\$ 5$, which is higher than the real value of B's signal, that is, the bad news seems to be hidden in this case. Arbitrageurs' expected stock price is $(\$ 5+\$ 15) / 2=\$ 10$, which is equal to the current price and this is the equilibrium state in the stock market. Now let's look at the derivative market. Since A believes the stock price should be $\$ 15$, A will buy $\$ 15-\$ 10=\$ 5$ stock in the derivative market, or, to be exact, A will take a long position of the derivative of the stock, and the implied stock value of the derivative position are from $\$ 10$ to $\$ 15$. As for investor $\mathrm{B}$, he will short $\$ 10-\$ 3=\$ 7$ stocks in the derivative 
market. The net position from investor A and B will be a short position of $\$ 2$. The arbitrageurs will clear the market and the implied stock price in the derivative market will be $\$ 10-\$ 2=\$ 8$. Right now, arbitrageurs have different price information in the stock market and derivatives market. We assume that the arbitrageurs have the same confidence in the two markets, thus the final price given by the arbitrageurs is the mean of the two-market price, $(\$ 10+\$ 8) / 2=\$ 9$, which is equal to the rational price.

At time 2, the optimistic investor A gets good news about the terminal dividend, say $\$ 18$. The rational price now is $(\$ 18+\$ 3) / 2=\$ 10.5$. The arbitrageurs will see A`s signal when the price is less than $\$ 18$. At the same time, based on their information from time 1 , their expectation of B`s signal is $\$ 10 / 2=\$ 5$. The initial stock price at time 2 will be $(\$ 18+$ $\$ 5) / 2=\$ 11.5$ (see the proof of Lemma 6 in Appendix). The bad news keeps hidden in this case. Investor A will long $\$ 6.5$ stock in the derivative market and investor B will short $\$ 8.5$ stock in the derivative market, and the implied stock price in the derivative market is $\$ 11.5+(\$ 6.5-\$ 8.5)=\$ 9.5$. Since the arbitrageurs have the same confidence in the two markets, the final price in this case will be $(\$ 11.5+\$ 9.5) / 2=\$ 10.5$, which is equal to the rational price.

At time 3, the real dividend happened, and we assume that it is equal to the mean of $\mathrm{A}$ and $\mathrm{B}$ 's signal $(\$ 18+\$ 3) / 2=\$ 10.5$. The whole story is shown in the table below.

Table 1. A simple case.

\begin{tabular}{llll}
\hline Time & Rational Price & Single Market (Bias with the rational price) & Two Market (Bias with the rational price) \\
\hline 0 & $\$ 12.5$ & $\$ 12.5(\$ 0)$ & $\$ 12.5(\$ 0)$ \\
1 & $\$ 9$ & $\$ 10(\$ 1)$ & $\$ 9(\$ 0)$ \\
2 & $\$ 10.5$ & $\$ 11.5(\$ 1)$ & $\$ 10.5(\$ 0)$ \\
3 & $\$ 10.5$ & $\$ 10.5(\$ 0)$ & $\$ 10.5(\$ 0)$ \\
\hline
\end{tabular}

According to Table 1, the stock price is overpriced at both time 1 and time 2 because the bad news is hidden in these times. These irrational higher prices result in a stock price crash in time 3. But if there is a perfect derivative market in where the stock can be short or long precisely and without any transaction cost, as long as the arbitrageurs give the derivative market the same trust as the stock market, the final stock price will be the same as the rational price, the price can be displayed quickly and accurately. This decreases the probability of stock crash.

To put it simply, the above story is that if the negative information is released first, the initial pricing given by the stock market is likely to be high due to the short sell constraint on the stock market. What's more, the release of good information after that will further push up share prices, and negative information will continue to be hidden. The accumulation of negative information and the continued overestimation of the stock price will result in a stock price crash after the release of real information.

But if there is a derivative market with no short sell constraint, the stock price will be adjusted in the derivatives market and some signals will be sent to the stock market. Such a mechanism is conducive to better release of information and to make stock prices more reasonable.

The impact of derivatives markets on information flows can be affected in many ways, such as differences in transaction costs between long and short trades, the frictions of information flows between derivatives markets and stock markets. We'll discuss more details in the following section.

\section{Model}

\subsection{A Basic Model}

Time 1: the potential for hidden information

At time1, the only private information is held by investor B. Similar to Hong and Stein (2003) [13], there is a cutoff value for $S_{B}$ such that B's signal will be hidden when $S_{B}$ is less than this cutoff value.

Lemma 2. The cut off value for $S_{B}$ is

$$
S_{B}^{*}=\frac{2}{3}(V+H)
$$

Then for all values of $S_{B}>S_{B}^{*}$, there must be revelation of $S_{B}$. The final price will be

$$
P_{1}^{F}=\left\{\begin{array}{c}
\frac{V+H+S_{B}}{2}+\theta\left(c_{1}-c_{2}\right) \frac{(V+H)-S_{B}}{2}, \text { if } \frac{2}{3}(V+H)<S_{B} \leq V+H \\
\frac{V+H+S_{B}}{2}+\theta\left(c_{1}-c_{2}\right) \frac{S_{B}-(V+H)}{2}, \text { if } V+H<S_{B}
\end{array}\right.
$$

We call these Case $11\left(V+H<S_{B}\right)$ and Case $12\left(\frac{2}{3}(V+H)<S_{B} \leq V+H\right)$.

Lemma 3. For all values of $S_{B} \leq S_{B}^{*}, S_{B}$ will be hidden and the final price will be

$$
P_{1}^{F}=\frac{2}{3}(V+H)+\theta\left(c_{1}\left(V+H-\frac{2}{3}(V+H)\right)+c_{2}\left(S_{B}-\frac{2}{3}(V+H)\right)\right)
$$

We call this Case 2

Case 11 tells us a story that when $S_{B}$ is "very high" (higher than the ex-ante expectation of A`s signal), B`s signal will be revealed and the bullish investor B will long the stock in both markets while A can only short the stock on the derivative market.

As for Case 12, let's consider a scenario where the auctioneer start announcing a price $2 \mathrm{~V}+\mathrm{H}$, and the 
arbitrageurs' demand is certain to be negative. Then the auctioneer lowers the price, for any price $V+H>p_{1}>S_{B}^{*}=$ $\frac{2}{3}(V+H)$, investor A will long the stock and the arbitrageurs' demand will be $\mathrm{E}\left[D \mid S_{B} \leq p_{1}\right]-p_{1}=\frac{V+H}{2}+\frac{p_{1}}{4}-p_{1}=$ $\frac{V+H}{2}-\frac{3 p_{1}}{4}<0$, the auctioneer will keep lowering the price. But since $S_{B}>S_{B}^{*}$, when the auctioneer announcing a price $S_{B}$, investor B will long the stock and the arbitrageurs see B`s signal and their demand will be $\frac{V+H+S_{B}}{2}-S_{B}=\frac{V+H-S_{B}}{2}>0$, the auctioneer will raise the price until $p_{1}=\frac{V+H+S_{B}}{2}$, where the arbitrageurs` demand is zero. This case tells us that when $S_{B}$ is "moderately high", B`s signal will be revealed. But the stock price is higher than his information, thus B will short the stock at the derivative market.

Case 2 is similar to Case 12 at first, but since $S_{B} \leq S_{B}^{*}$, the auctioneer will lower the price until $p_{1}=S_{B}^{*} \geq S_{B}$ at where the arbitrageurs` demand is zero. In this case, B`s signal will be hidden and the initial stock price is higher than the rational expectation $\frac{V+H+S_{B}}{2}$. But because B can short the stock market in the derivatives market, the final price, compared to the single market case, may be closer to the rational expectation. For instance, when $c_{1}=c_{2}=1, \theta=\frac{1}{2}, P_{1}^{F}=\frac{2}{3}(V+H)+$ $\frac{1}{2}\left(V+H+S_{B}-\frac{4}{3}(V+H)\right)=\frac{V+H+S_{B}}{2}$.

Time 2: previously hidden information may be revealed

The above analysis shows that $S_{B}$ may not be immediately revealed when $S_{B}$ is low enough. But at time 2, investor A gets his signal $S_{A}$, more information of $S_{B}$ may come out if $S_{A}$ is small enough,

Case 1: B`s signal was revealed at time 1. This case is much

$$
P_{2}^{F}=\frac{S_{A}}{2}+\frac{V+H}{6}+\theta\left(c_{1}\left(S_{A}-\left(\frac{S_{A}}{2}+\frac{V+H}{6}\right)\right)+c_{2}\left(S_{B}-\left(\frac{S_{A}}{2}+\frac{V+H}{6}\right)\right)\right)
$$

We call this Case $2 \mathrm{~A}$

Lemma 7. Assume that $S_{B}$ was hidden at time 1, and $S_{A}<V+H$. Let the new cutoff value of $S_{B}$

$$
S_{B}^{* *}=\frac{2 S_{A}}{3}
$$

If $S_{B} \leq S_{B}^{* *}$, then $S_{A}$ will be revealed and $S_{B}$ continues to be hidden at time 2 . The final price is given by

$$
P_{2}^{F}=\frac{2 S_{A}}{3}+\theta\left(c_{1}\left(S_{A}-\frac{2 S_{A}}{3}\right)+c_{2}\left(S_{B}-\frac{2 S_{A}}{3}\right)\right)
$$

We call this Case 2B

Lemma 8. Assume that $S_{B}$ was hidden at time 1, and $S_{A}<V+H$. As in Lemma 3, the cutoff value of $S_{A}$

$$
S_{A}^{*}=\frac{2 S_{B}+H}{3}
$$

similar to time 1. $S_{A}$ will be hidden if it is small enough.

Lemma 4. Assume that $S_{B}$ has been revealed at time 1. Let the cutoff value for $S_{A}$ be

$$
S_{A}^{*}=\frac{2 S_{B}+H}{3}
$$

For all values of $S_{A}>S_{A}^{*}, S_{A}$ will be revealed at time 2, and

$$
P_{2}^{F}=\left\{\begin{array}{c}
\frac{S_{A}+S_{B}}{2}+\theta\left(c_{1}-c_{2}\right) \frac{S_{A}-S_{B}}{2}, \text { if } S_{B}<S_{A} \\
\frac{S_{A}+S_{B}}{2}+\theta\left(c_{1}-c_{2}\right) \frac{S_{B}-S_{A}}{2}, \text { if } \frac{2 S_{B}+H}{3}<S_{A} \leq S_{B}
\end{array}\right.
$$

We call these Case $1 \mathrm{~A} 1\left(S_{B}<S_{A}\right)$ and Case 1A2 $\left(\frac{2 S_{B}+H}{3}<\right.$ $\left.S_{A} \leq S_{B}\right)$

Lemma 5. Assume that $S_{B}$ has been revealed at time 1. For all values of $S_{A} \leq S_{A}^{*}, S_{A}$ will be hidden at time 2 , and

$$
P_{2}^{F}=\frac{2 S_{B}+H}{3}+\theta\left(c_{2}\left(S_{A}-\frac{2 S_{B}+H}{3}\right)+c_{1}\left(S_{B}-\frac{2 S_{B}+H}{3}\right)\right)
$$

We call this Case $1 \mathrm{~B}$

Case 2: B`s signal was hidden at time 1. This case is more complicated. Intuitively, we believe that the relationship between $S_{A}$ and $S_{B}$ affects the release of $S_{A}$ and $S_{B}$. There are three possible results: $S_{B}$ keep hidden and $S_{A}$ is revealed; $S_{A}$ is small enough so that $S_{B}$ is revealed; both $S_{A}$ and $S_{B}$ are revealed.

Lemma 6. Assume that $S_{B}$ was hidden at time 1. If $S_{A}>V+H$, then $S_{A}$ is revealed and $S_{B}$ continues to be hidden at time 2 . The final price is given by
If $S_{A} \leq S_{A}^{*}$ and $S_{B}>H$, then $S_{B}$ will be revealed and $S_{A}$ will be hidden at time 2 . The final price is given by

$$
P_{2}^{F}=\frac{2 S_{B}+H}{3}+\theta\left(c_{2}\left(S_{A}-\frac{2 S_{B}+H}{3}\right)+c_{1}\left(S_{B}-\frac{2 S_{B}+H}{3}\right)\right)
$$

We call this Case $2 \mathrm{C}$

Lemma 9. Assume that $S_{B}$ was hidden at time 1. For any values that not already covered in case $1 \mathrm{~A} 1,1 \mathrm{~A} 2,1 \mathrm{~B}, 2 \mathrm{~A}, 2 \mathrm{~B}$ and $2 \mathrm{C}$. Both $S_{A}$ and $S_{B}$ will be revealed and we have

$$
P_{2}^{F}=\left\{\begin{array}{l}
\frac{S_{A}+S_{B}}{2}+\theta\left(c_{1}-c_{2}\right) \frac{S_{A}-S_{B}}{2}, \text { if } S_{A}>S_{B} \\
\frac{S_{A}+S_{B}}{2}+\theta\left(c_{1}-c_{2}\right) \frac{S_{B}-S_{A}}{2}, \text { if } S_{A} \leq S_{B}
\end{array}\right.
$$

We call these Case 2D1 $\left(S_{A}>S_{B}\right)$ and Case 2D2 $\left(S_{A}>S_{B}\right)$ The total story at time 2 is shown in Figure 1 


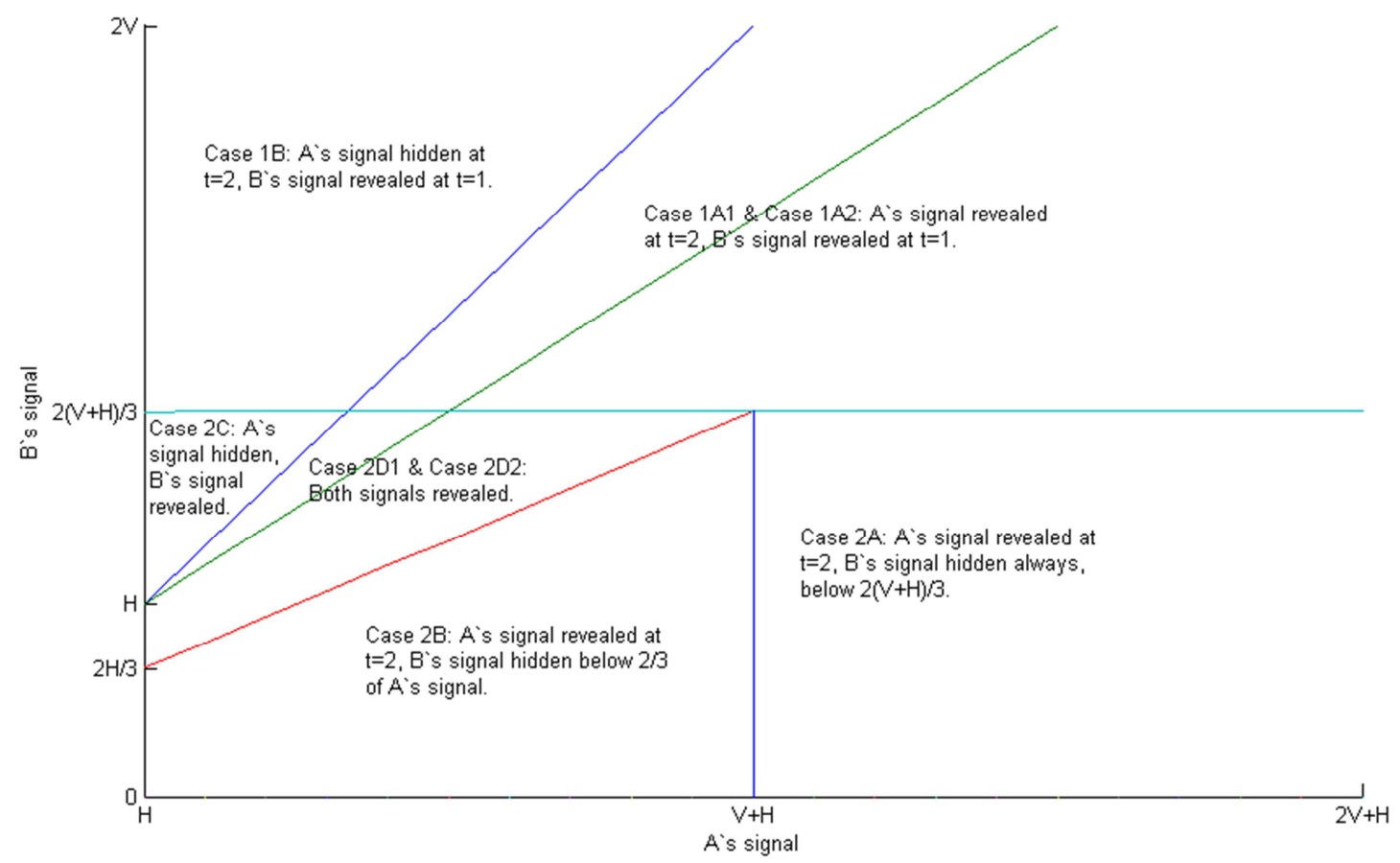

Figure 1. Partition of equilibrium outcomes at time 2, depending on $S_{A}$ and $S_{B}$.

\subsection{General Equilibrium}

\subsubsection{Extend to Infinite Adjustment}

In the previous analysis, we assumed that the derivative market can adjust the stock price only once at each period. Now we extend the single adjustment to the infinite adjustment, that is, for an initial stock price $P^{S}$, investor A and $B$ will long and short the stock in the derivative market and the final price $P^{F}$ will be a little different from $P^{S}$. Then investors will long or short the stock based on the new stock price $P^{F}$, and this is the second adjustment of the price. We repeat this adjustment infinitely andthe final result is shown below.

\section{Case Condition}

Time 0

All values

Final price

Time 1

$$
\begin{array}{llr}
11 & V+H<S_{B} & \frac{V+H+S_{B}}{2}+\left(w_{1}-w_{2}\right) \frac{(V+H)-S_{B}}{2} \\
12 & \frac{2}{3}(V+H)<S_{B} \leq V+H & \frac{V+H+S_{B}}{2}+\left(w_{1}-w_{2}\right) \frac{S_{B}-(V+H)}{2} \\
2 & S_{B} \leq \frac{2}{3}(V+H) & \frac{2(V+H)}{3}+w_{1}\left(V+H-\frac{2(V+H)}{3}\right) \\
& +w_{2}\left(S_{B}-\frac{2(V+H)}{3}\right)
\end{array}
$$$$
\mathrm{V}+\frac{H}{2}+\left(w_{1}-w_{2}\right) \frac{H}{2}
$$

Proposition 1. If the derivatives market can adjust the prices enough. If $\theta \neq 0, c_{1}+c_{2} \neq 0$ and $\theta\left(c_{1}+c_{2}\right) \neq 2$, the final price is only about $c_{1}$ and $c_{1}$ and has nothing to do with $\theta$.

Lemma 10. If the derivatives market can adjust the prices enough. The final price in each case are shown in Table 1.

Table 1. The final price at difference cases, after an infinite adjustment from the derivative market

$$
w_{1}=\frac{c_{1}}{c_{1}+c_{2}}, w_{2}=1-w_{1}=\frac{c_{2}}{c_{1}+c_{2}}
$$

$$
\begin{array}{lll}
\text { A`s signal } & \text { B`s signal } & \text { Story } \\
\text { No } & \text { No } & \text { Initial stock price at } \\
\text { Information } & \text { Information } & \text { time } 0
\end{array}
$$

Time 2

$$
\begin{array}{ll}
1 \mathrm{~A} 1 & S_{A}>\frac{2 S_{B}+H}{3}, S_{B} \\
& >\frac{2(V+H)}{3}, S_{A}>S_{B} \\
1 \mathrm{~A} 2 & S_{A}>\frac{2 S_{B}+H}{3}, S_{B} \\
& >\frac{2(V+H)}{3}, S_{A} \leq S_{B}
\end{array}
$$

No Information Revealed

No

Information

Revealed

No

Information Revealed
$S_{B}$ is big enough and revealed

$S_{B}$ is relatively big and revealed

$S_{B}$ is small and failed to be revealed
$S_{B}$ revealed at $\mathrm{t}=1$,

Revealed Revealed

$S_{A}$ is big enough and be revealed at $\mathrm{t}=2$

$S_{B}$ revealed at $\mathrm{t}=1$,

Revealed Revealed $S_{A}$ is big enough and be revealed at $\mathrm{t}=2$ 
$1 \mathrm{~B}$

$$
\begin{aligned}
& S_{A} \leq \frac{2 S_{B}+H}{3}, S_{B} \\
& >\frac{2(V+H)}{3}
\end{aligned}
$$

$2 \mathrm{~A}$

$$
\begin{aligned}
& S_{A}>\mathrm{V}+\mathrm{H}, S_{B} \\
& \leq \frac{2(V+H)}{3}
\end{aligned}
$$

Not Revealed$$
\frac{S_{A}}{2}+\frac{V+H}{6}+w_{1}\left(S_{A}-\left(\frac{S_{A}}{2}+\frac{V+H}{6}\right)\right)
$$$$
+w_{2}\left(S_{B}\right.
$$

Revealed

$$
\left.-\left(\frac{S_{A}}{2}+\frac{V+H}{6}\right)\right)
$$

$$
S_{A} \leq \mathrm{V}+\mathrm{H}, S_{B} \leq \frac{2 S_{A}}{3} \quad \frac{2 S_{A}}{3}+w_{1}\left(S_{A}-\frac{2 S_{A}}{3}\right)+w_{2}\left(S_{B}-\frac{2 S_{A}}{3}\right)
$$

Revealed

Not

Revealed

Revealed

Revealed

Revealed
Not

Revealed

$S_{B}$ revealed at $\mathrm{t}=1$, $S_{A}$ is small and be hidden at $\mathrm{t}=2$

$S_{B}$ is hidden at $\mathrm{t}=1$, $S_{A}$ is very big so that Revealed $\quad S_{A}$ is revealed at $\mathrm{t}=2$ and $S_{B}$ keep hidden in $\mathrm{t}=2$

$S_{B}$ is hidden at $\mathrm{t}=1$, $S_{A}$ is small but considerably bigger than $S_{B}$ so that $S_{A}$ is revealed at $\mathrm{t}=2$ and $S_{B}$ keep hidden in $\mathrm{t}=2$

$S_{B}$ is hidden at $\mathrm{t}=1$, $S_{A}$ is considerably smaller than $S_{B}$ so that $S_{B}$ is revealed at $\mathrm{t}=2$ and $S_{A}$ keep hidden in $\mathrm{t}=2$ $S_{B}$ is hidden at $\mathrm{t}=1$, but the gap between $S_{A}$ and $S_{B}$ is not very big so that $S_{A}$ and $S_{B}$ are both revealed at $\mathrm{t}=2$ $S_{B}$ is hidden at $\mathrm{t}=1$, but the gap between $S_{A}$ and $S_{B}$ is not very big so that $S_{A}$ and $S_{B}$ are both revealed at $\mathrm{t}=2$

Dividend happens, all investors know the real value.

\subsubsection{Implications for Return Asymmetries}

We define the return at day $t$ as

$$
R_{t}=P_{t}^{F}-P_{t-1}^{F}
$$

We use the skewness to measure the asymmetries in the return distribution

$$
S k w_{t}=E\left[R_{t}^{3}\right], \mathrm{t}=1,2,3
$$

And we define overall unconditional skewness of short-horizon return as the average skewness over the period

$$
S k w_{t}^{S}=\frac{\sum_{i=1}^{t} S k w_{i}^{3}}{t}=\frac{\sum_{i=1}^{t} R_{i}^{3}}{t}, \mathrm{t}=1,2,3
$$

We also define the stock crash as a negative skewness.

Proposition 2. If the derivatives market can adjust the prices enough. When $c_{1}=c_{2}$, the skewness at every day and the unconditional skewness over any periods are 0 .
Revealed Revealed
This conclusion is in line with our intuition, that is, a better short-sell environment in the derivative market can effectively promote the release of information. In reality, if we assume that there is no cost to construct a long position in the derivative market $\left(c_{1}=1\right)$, when the short sell cost is zero $\left(c_{2}=1\right)$, the exist of derivative will eliminate the stock crash.

Proposition 3. If the derivatives market can adjust the prices enough. If $c_{2}<c_{1}$, no matter how much the differences of opinions $(\mathrm{H} / 2 \mathrm{~V})$ is, the skewness at day 1 and day 2 are greater or equal to 0 . But there will be a huge negative skewness at day 3 so that the overall skewness turns into negative in many cases after day 3 .

This results can be seen in Figure 2 and Figure 3. Given $c_{1}=1$, Figure 2 and Figure 3 show us the relationship between the skewness (daily skewness in Figure 2 and average skewness in Figure 3) and the heterogeneous opinion at different levels of short-sell cost. In Figure 2, we find out that when the short sell cost is great than 0 , skewness in time 1 and time 2 is equal or higher than zero, which means an increase in 
price, but a huge negative skewness appears at time 3 so that the average skewness over 3 days becomes negative in Figure 3 , especially when the difference of opinions is higher. Also, the range of variation of skewness increases with the increase in the short sell cost.
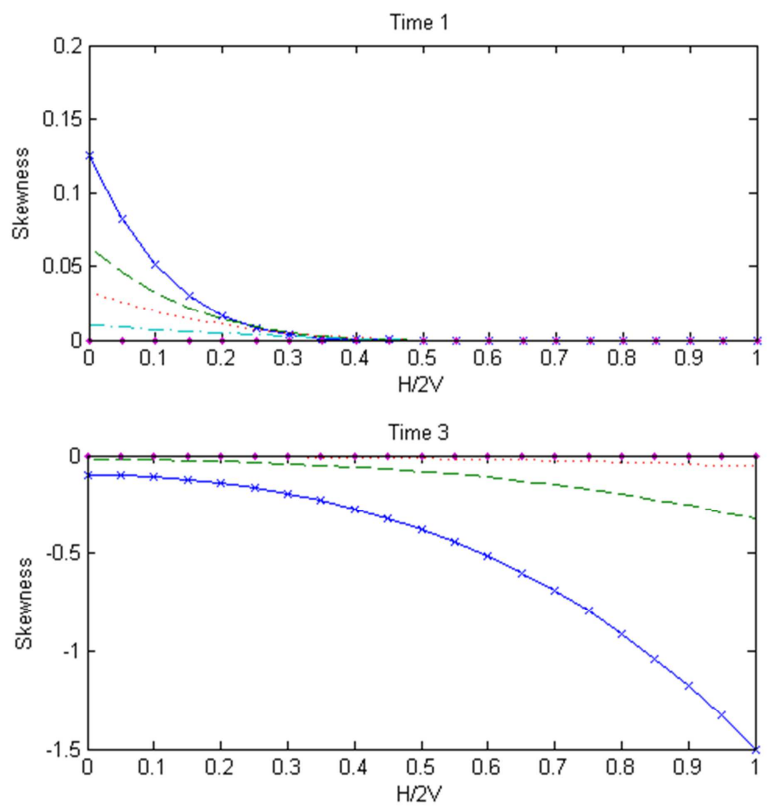

Figure 2. Daily Skewness and differences of opinions.
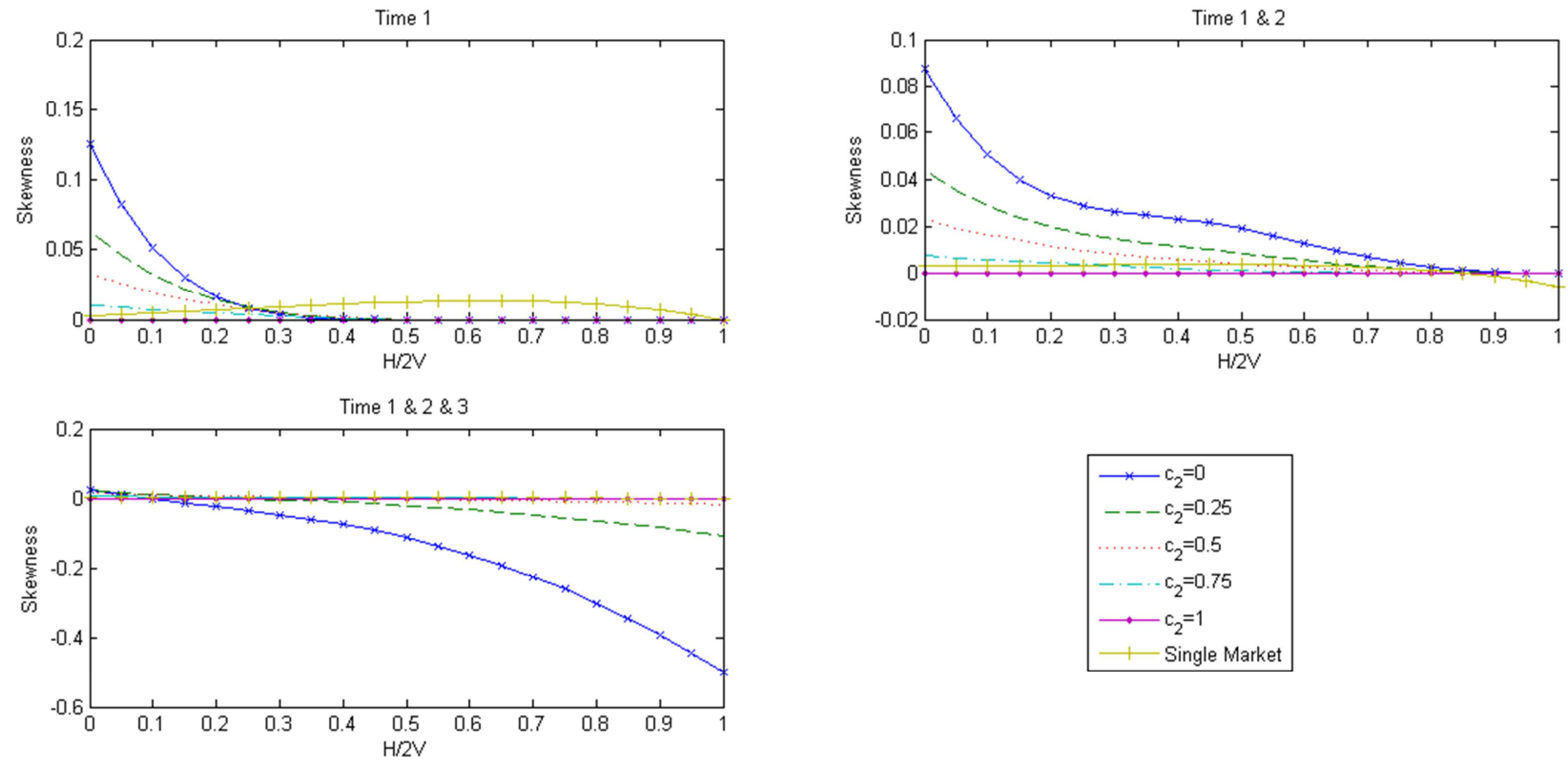

This conclusion proves that a derivatives market may reduce the stock crash if the short sell environment is good enough. With the deterioration of the short environment, the derivative may also increase the probability and level of stock crash.
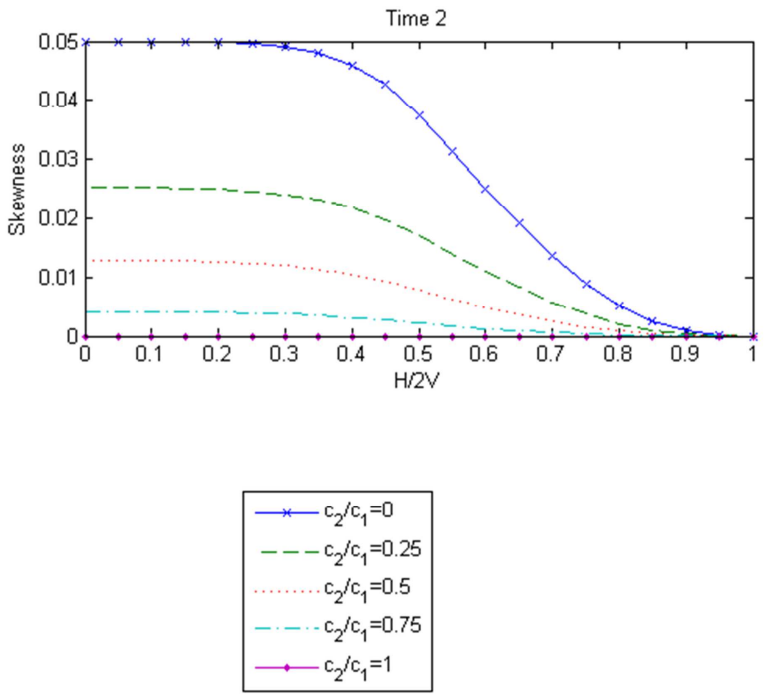

Figure 3. Overall skewness and differences of opinions.

Proposition 4. If the derivatives market can adjust the prices enough. The skewness is more negative for a higher level of differences of opinions, but a better short sell environment can reduce the skewness difference.

This result is clearly reflected in Figure 4. In Figure 4, a higher level of opinion difference corresponds to a lower curve. But as the short sell cost decreasing, all the curves are closer to 0 , and the distances between these curves are significantly reduced. 


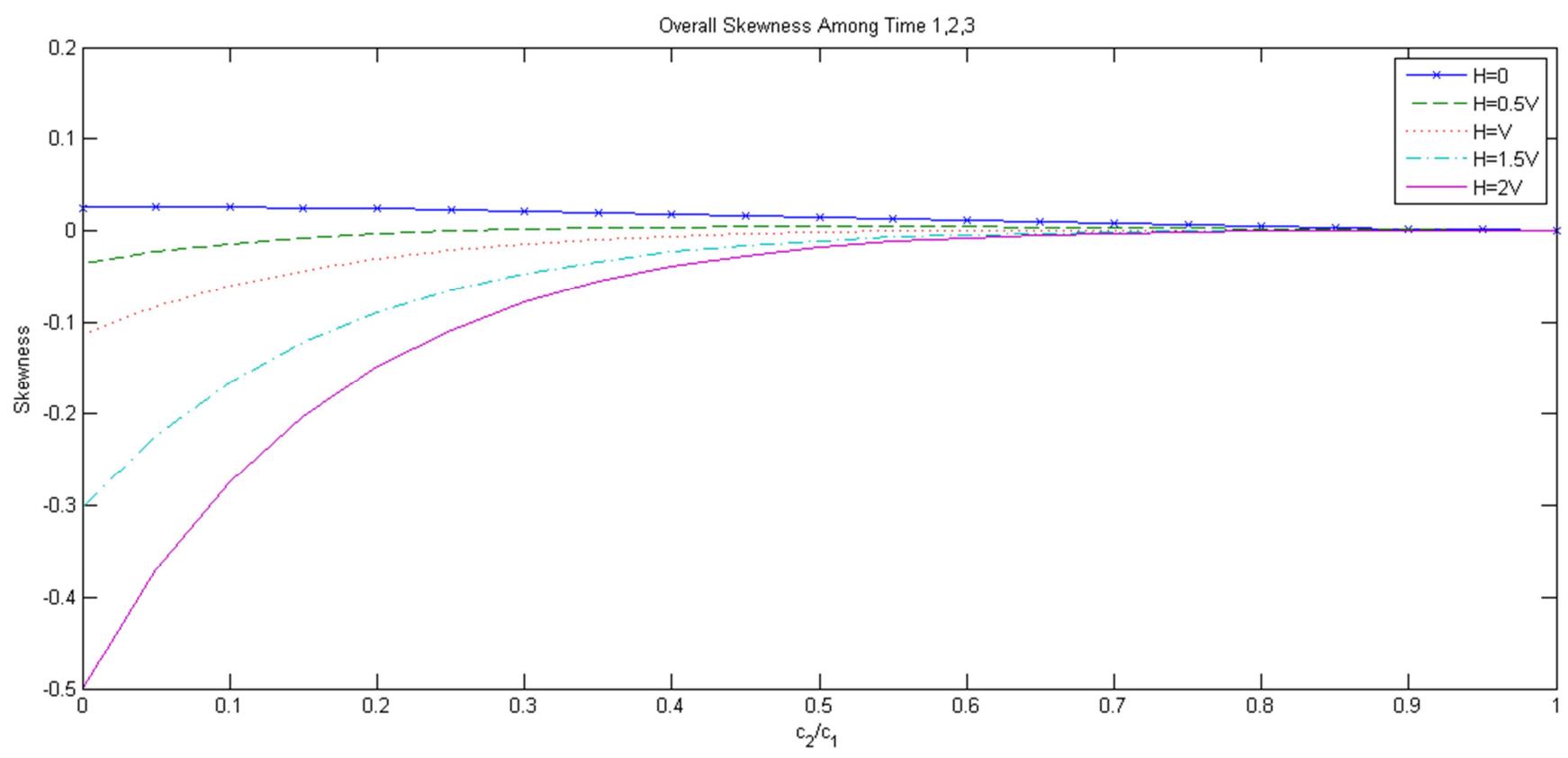

Figure 4. Overall skewness and short-sell cost.

\section{Conclusion}

We construct a four-period-double-market model in this paper. By including the stock market with short selling restrictions and the derivative market without short selling restrictions but with long-short costs in the model, we study the relationship between the asymmetry of long-short cost in derivative market, investors' heterogeneous beliefs and the stock price crash risk.

The asymmetry of short cost in derivatives market will distort the implied price of derivatives market, which will send a wrong message to stock market and intertwined with investors' heterogeneous beliefs in the stock market. Finally, due to the existence of shorting restrictions in the stock market, the risk of stock price risk in the stock market is now different with the single market.

Under the general equilibrium conditions, a derivative

$$
P^{F}=(1-\theta) P^{S}+\theta P^{O}=P^{S}+\theta\left(c_{1}\left(P_{A}-P^{S}\right)+c_{2}\left(P_{B}-P^{S}\right)\right)>P_{S}+\theta c_{2}\left(P_{B}-P^{S}\right) \geq P_{S}+P_{B}-P^{S}=P_{B}
$$

Thus, $P_{B}$ will keep silence after the adjustment.

Proof of Lemma 2. According to Lemma 1, if $S_{B}$ is hidden at the stock market, it will keep hidden after the adjustment from the derivative market.

In the stock market, since $S_{B}$ is uniform on $[0,2 \mathrm{~V}]$, if investor $\mathrm{B}$ has not submitted an order at trial price $p_{1}$, the arbitrageurs` forecast of $S_{B}$ is

$$
\mathrm{E}\left[S_{B} \mid S_{B} \leq p_{1}\right]=\frac{p_{1}}{2}
$$

Hence the risk-neutral arbitrageurs` estimate of the terminal value of the asset is

$$
\begin{array}{cc}
\mathrm{E}\left[D \mid S_{B} \leq p_{1}\right]=\frac{V+H}{2}+\frac{p_{1}}{4} \quad \text { (26) } \quad P_{1}^{S}=\frac{V+H+S_{B}}{2} \\
P_{1}^{F}=P_{1}^{S}+\theta\left(c_{1}\left(V+H-P_{1}^{S}\right)+c_{2}\left(S_{B}-P_{1}^{S}\right)\right)=\frac{V+H+S_{B}}{2}+\theta\left(c_{1}-c_{2}\right) \frac{S_{B}-(V+H)}{2}
\end{array}
$$
demand of the arbitrageur is zero. initial stock price will be market with symmetrical long-short cost can completely eliminate the risk of stock price crash. But if the short-selling cost is higher than the buying cost, the stock price will be overvalued in the early periods, and the negative events will bring more serious stock price crash than the single market

\section{Appendix}

\section{Appendix A: Proofs of Lemmas}

Proof of Lemma 1. Given the initial stock price $P^{S}$ and the expected value of investor $\mathrm{A}$ and $\mathrm{B}$ are $P_{A}$ and $P_{B}$, let $\theta, c_{1}, c_{2} \in[0,1]$, let $P_{A}>P^{S}>P_{B}$. Since $P^{S}>P_{B}$, B will not submit an order for the auction price is higher than his expectation. situation.

If B keep silence, the auctioneer will lower $p_{1}$ until the net

$$
p_{1}=\frac{V+H}{2}+\frac{p_{1}}{4} \Rightarrow p_{1}=\frac{2}{3}(V+H)
$$

That is, the lowest price the auctioneer can give is $\frac{2}{3}(V+H)$. So, if $S_{B}<\frac{2}{3}(V+H)$, B`s information will be hidden. Let $S_{B}^{*}=\frac{2}{3}(V+H)$ be the cutoff value of $S_{B}$.

When $S_{B}>S_{B}^{*}$, B`s information will be revealed and the 


$$
\begin{gathered}
\text { If } \frac{2}{3}(V+H)<S_{B} \leq V+H \\
P_{1}^{F}=P_{1}^{S}+\theta\left(c_{1}\left(S_{B}-P_{1}^{S}\right)+c_{2}\left(V+H-P_{1}^{S}\right)\right)=\frac{V+H+S_{B}}{2}+\theta\left(c_{1}-c_{2}\right) \frac{(V+H)-S_{B}}{2}
\end{gathered}
$$

Proof of Lemma 3. Since $S_{B} \leq S_{B}^{*}$,

$$
P_{1}^{S}=\mathrm{E}\left[D \mid S_{B} \leq S_{B}^{*}\right]=\frac{V+H}{2}+\frac{S_{B}^{*}}{4}=\frac{2}{3}(V+H)
$$

Also, since $S_{B} \leq S_{B}^{*}=\frac{2}{3}(V+H)<V+H$

$$
P_{1}^{F}=P_{1}^{S}+\theta\left(c_{1}\left(V+H-P_{1}^{S}\right)+c_{2}\left(S_{B}-P_{1}^{S}\right)\right)=\frac{2}{3}(V+H)+\theta\left(c_{1}\left(V+H-\frac{2}{3}(V+H)\right)+c_{2}\left(S_{B}-\frac{2}{3}(V+H)\right)\right)
$$

Proof of Lemma 4. According to Lemma 1, if $S_{A}$ is hidden at the stock market, it will keep hidden after the adjustment from the derivative market. Since $S_{A}$ is uniform on $[\mathrm{H}, 2 \mathrm{~V}+$ $\mathrm{H}]$, if investor $\mathrm{A}$ has not submitted an order at trial price $p_{2}$, the arbitrageurs' forecast of $S_{A}$ is

$$
\mathrm{E}\left[S_{A} \mid S_{A} \leq p_{2}\right]=\frac{H+p_{2}}{2}
$$

Hence the risk-neutral arbitrageurs` estimate of the terminal value of the asset is

$$
\mathrm{E}\left[D \mid S_{A} \leq p_{2}\right]=\frac{H+p_{2}}{4}+\frac{S_{B}}{2}
$$

If $S_{A}>S_{B}$

$$
P_{2}^{F}=P_{2}^{S}+\theta\left(c_{1}\left(S_{A}-P_{2}^{S}\right)+c_{2}\left(S_{B}-P_{2}^{S}\right)\right)=\frac{S_{A}+S_{B}}{2}+\theta\left(c_{1}-c_{2}\right) \frac{S_{A}-S_{B}}{2}
$$

If $\frac{2 S_{B}+H}{3}<S_{A} \leq S_{B}$

$$
P_{2}^{F}=P_{2}^{S}+\theta\left(c_{1}\left(S_{B}-P_{2}^{S}\right)+c_{2}\left(S_{A}-P_{2}^{S}\right)\right)=\frac{S_{A}+S_{B}}{2}+\theta\left(c_{1}-c_{2}\right) \frac{S_{B}-S_{A}}{2}
$$

Proof of Lemma 5. Since $S_{A} \leq S_{A}^{*}$,

$$
P_{2}^{S}=\mathrm{E}\left[D \mid S_{A} \leq S_{A}^{*}\right]=\frac{S_{B}}{2}+\frac{S_{A}^{*}+H}{4}=\frac{2 S_{B}+H}{3}
$$

Also, since $S_{B}$ was revealed, $S_{B}>S_{B}^{*}=\frac{2}{3}(V+H)$

$$
S_{B}-\frac{2 S_{B}+H}{3}=\frac{S_{B}-H}{3}>\frac{2(V+H)-3 H}{9}=\frac{2 V-H}{9} \geq 0 \Rightarrow S_{B}>\frac{2 S_{B}+H}{3} \geq S_{A}
$$

Thus, the final price will be

$$
P_{2}^{F}=P_{2}^{S}+\theta\left(c_{1}\left(S_{A}-P_{2}^{S}\right)+c_{2}\left(S_{B}-P_{2}^{S}\right)\right)=\frac{2 S_{B}+H}{3}+\theta\left(c_{2}\left(S_{A}-\frac{2 S_{B}+H}{3}\right)+c_{1}\left(S_{B}-\frac{2 S_{B}+H}{3}\right)\right)
$$

Proof of Lemma 6. Since $S_{B} \leq S_{B}^{*}=\frac{2}{3}(V+H)$ and $S_{B}$ was hidden at time 1. $S_{A}$ will be revealed if $S_{A}>\frac{2}{3}(V+H)$ and the initial stock price will be

$$
P_{2}^{S}=\frac{S_{A}}{2}+\frac{S_{B}^{*}}{4}
$$

If $S_{A}>V+H$

$$
P_{2}^{S}=\frac{S_{A}}{2}+\frac{S_{B}^{*}}{4}>\frac{\mathrm{V}+\mathrm{H}}{2}+\frac{S_{B}^{*}}{4}=\frac{2}{3}(\mathrm{~V}+\mathrm{H})=S_{B}^{*} \geq S_{B}
$$

Thus, $S_{B}$ will keep hidden in this case. Since $S_{B} \leq P_{2}^{S}<S_{A}$ and the final price will be 


$$
P_{2}^{F}=P_{2}^{S}+\theta\left(c_{1}\left(S_{A}-P_{2}^{S}\right)+c_{2}\left(S_{B}-P_{2}^{S}\right)\right)=\frac{S_{A}}{2}+\frac{V+H}{6}+\theta\left(c_{1}\left(S_{A}-\left(\frac{S_{A}}{2}+\frac{V+H}{6}\right)\right)+c_{2}\left(S_{B}-\left(\frac{S_{A}}{2}+\frac{V+H}{6}\right)\right)\right)
$$

Proof of Lemma 7. When $S_{A}$ is revealed first, when $S_{B}$ is hidden at a price $p_{2}$

$$
\mathrm{E}\left[S_{B} \mid S_{B} \leq p_{2}\right]=\frac{p_{2}}{2}
$$

The risk-neutral arbitrageurs` estimate of the terminal value of the asset is

$$
\mathrm{E}\left[D \mid S_{B} \leq p_{2}\right]=\frac{S_{A}}{2}+\frac{p_{2}}{4}
$$

If B keep silence, the auctioneer will lower $p_{2}$ until the net demand of the arbitrageur is zero.

$$
p_{2}=\frac{S_{A}}{2}+\frac{p_{2}}{4} \Rightarrow p_{2}=\frac{2}{3} S_{A}
$$

That is, the lowest price the auctioneer can give is $\frac{2}{3}(V+H)$. So, if $S_{B}<\frac{2}{3} S_{A}$, B`s information will be hidden. Let $S_{B}^{* *}=\frac{2}{3} S_{A}$ be the new cutoff value of $S_{B}$.

If $S_{B} \leq S_{B}^{* *}$, then $S_{A}$ will be revealed and $S_{B}$ continues to be hidden at time 2 . The initial stock price will be

$$
P_{2}^{S}=\frac{S_{A}}{2}+\frac{S_{B}^{* *}}{4}=\frac{2 S_{A}}{3}
$$

It is easy to see that $S_{B}<P_{2}^{S}<S_{A}$ and the final price is

$$
\begin{gathered}
P_{2}^{F}=P_{2}^{S}+\theta\left(c_{1}\left(S_{A}-P_{2}^{S}\right)+c_{2}\left(S_{B}-P_{2}^{S}\right)\right)=\frac{2 S_{A}}{3}+ \\
\theta\left(c_{1}\left(S_{A}-\frac{2 S_{A}}{3}\right)+c_{2}\left(S_{B}-\frac{2 S_{A}}{3}\right)\right)
\end{gathered}
$$

Proof of Lemma 8. When $\frac{2}{3}(V+H) \geq S_{B}>H$ and $S_{A} \leq S_{A}^{*}=\frac{2 S_{B}+H}{3}<\frac{2 S_{B}+S_{B}}{3}=S_{B}, S_{B}$ will be revealed before $S_{A}$. If $S_{A}$ is hidden at a price $p_{2}$

$$
\mathrm{E}\left[S_{A} \mid S_{A} \leq p_{2}\right]=\frac{H+p_{2}}{2}
$$

The risk-neutral arbitrageurs` estimate of the terminal value of the asset is

$$
\mathrm{E}\left[D \mid S_{A} \leq p_{2}\right]=\frac{H+p_{2}}{4}+\frac{S_{B}}{2}
$$

If A keep silence, the auctioneer will lower $p_{2}$ until the net demand of the arbitrageur is zero.

$$
p_{2}=\frac{H+p_{2}}{4}+\frac{S_{B}}{2} \Rightarrow p_{2}=\frac{2 S_{B}+H}{3}
$$

That is, the lowest price the auctioneer can give is $\frac{2 S_{B}+H}{3}$. So, if $S_{A}<S_{A}^{*}=\frac{2 S_{B}+H}{3}$, A's information will be hidden. The initial stock price will be

$$
P_{2}^{S}=\mathrm{E}\left[D \mid S_{A} \leq S_{A}^{*}\right]=\frac{S_{B}}{2}+\frac{S_{A}^{*}+H}{4}=\frac{2 S_{B}+H}{3}
$$

It is easy to see that $S_{A}<P_{2}^{S}<S_{B}$, and the final price will be

$$
\begin{array}{r}
P_{2}^{F}=P_{2}^{S}+\theta\left(c_{2}\left(S_{A}-P_{2}^{S}\right)+c_{1}\left(S_{B}-P_{2}^{S}\right)\right)=\frac{2 S_{A}}{3}+ \\
\theta\left(c_{2}\left(S_{A}-\frac{2 S_{B}+H}{3}\right)+c_{1}\left(S_{B}-\frac{2 S_{B}+H}{3}\right)\right)(54)
\end{array}
$$

Proof of Lemma 9. For any other cases that are not covered by Lemma 2 to Lemma 8 , both $S_{B}$ will be revealed at time 1 and $S_{A}$ will be revealed at time 2. According to Figure 1, when $S_{B} \in\left[\frac{2}{3} H, \frac{2}{3}(V+H)\right]$ and $S_{A} \in\left[\frac{2 S_{B}+H}{3}, \frac{3}{2} S_{B}\right]$ both signals will be revealed. This is one case that when $S_{B}$ is not too small and $S_{A}$ is not too far away from $S_{B}$.

The initial stock price will be

$$
P_{2}^{S}=\frac{S_{A}+S_{B}}{2}
$$

If $S_{A}>S_{B}$

$$
P_{2}^{F}=P_{2}^{S}+\theta\left(c_{1}\left(S_{A}-P_{2}^{S}\right)+c_{2}\left(S_{B}-P_{2}^{S}\right)\right)=\frac{S_{A}+S_{B}}{2}+\theta\left(c_{1}-c_{2}\right) \frac{S_{A}-S_{B}}{2}
$$

If $S_{A} \leq S_{B}$

$$
P_{2}^{F}=P_{2}^{S}+\theta\left(c_{2}\left(S_{A}-P_{2}^{S}\right)+c_{1}\left(S_{B}-P_{2}^{S}\right)\right)=\frac{S_{A}+S_{B}}{2}+\theta\left(c_{1}-c_{2}\right) \frac{S_{B}-S_{A}}{2}
$$

Proof of Lemma 10. Based on Proposition 1, if the derivatives market can adjust the prices enough

$$
P^{F}=P^{S}+\frac{c_{1}}{c_{1}+c_{2}}\left(P_{A}-P^{S}\right)+\frac{c_{2}}{c_{1}+c_{2}}\left(P_{B}-P^{S}\right)
$$

Where $P^{S}$ is the initial stock market price, $P_{A}$ and $P_{B}$ are the expected value of long side and short side investor, $w_{1}=\frac{c_{1}}{c_{1}+c_{2}}$ and $w_{2}=\frac{c_{2}}{c_{1}+c_{2}}=1-w_{1}$.

Compare to the case where the derivatives market can adjust the prices only once.

$$
P^{F}=P^{S}+\theta\left(c_{1}\left(P_{A}-P^{S}\right)+c_{2}\left(P_{B}-P^{S}\right)\right)
$$

We can treat that the general case as a special case when $\theta=\frac{1}{c_{1}+c_{2}}$. Then we can get all results in Table 1 .

\section{Appendix B: Proofs of Propositions}

Proof of Proposition 1. Given the initial stock price $P^{S}$ and the expected value of investor $\mathrm{A}$ and $\mathrm{B}$ are $P_{A}$ and $P_{B}$, let $\theta, c_{1}, c_{2} \in[0,1]$, let $P_{A}>P^{S}>P_{B}$, let $P_{t}^{F}$ be the final price after the $\mathrm{t}$-th adjustment by the derivative market.

Case 1. If $c_{1}=c_{2}=0$ or $\theta=0$

$$
P_{t}^{F} \equiv P^{S}
$$




$$
P^{F}=\lim _{\mathrm{t} \rightarrow \infty} P_{t}^{F}=P^{S}
$$

Case 2. If $c_{1}+c_{2} \neq 0$ and $\theta \neq 0$

$$
\begin{gathered}
P_{0}^{F}=P^{S} \\
P_{1}^{F}=P_{0}^{F}+\theta\left(c_{1}\left(P_{A}-P_{0}^{F}\right)+c_{2}\left(P_{B}-P_{0}^{F}\right)\right)
\end{gathered}
$$

According to Lemma 1, if the bad news was hidden at the initial stock price, it will keep hidden after the adjustment

$$
\begin{gathered}
P_{t}^{F}=P_{t-1}^{F}+\theta\left(c_{1}\left(P_{A}-P_{t-1}^{F}\right)+c_{2}\left(P_{B}-P_{t-1}^{F}\right)\right)=P_{t-1}^{F}\left(1-\theta\left(c_{1}+c_{2}\right)\right)+\theta\left(c_{1} P_{A}+c_{2} P_{B}\right) \\
P_{t}^{F}-\frac{c_{1} P_{A}+c_{2} P_{B}}{c_{1}+c_{2}}=\left(1-\theta\left(c_{1}+c_{2}\right)\right)\left(P_{t-1}^{F}-\frac{c_{1} P_{A}+c_{2} P_{B}}{c_{1}+c_{2}}\right) \\
P_{t}^{F}-\frac{c_{1} P_{A}+c_{2} P_{B}}{c_{1}+c_{2}}=\left(1-\theta\left(c_{1}+c_{2}\right)\right)^{t}\left(P_{0}^{F}-\frac{c_{1} P_{A}+c_{2} P_{B}}{c_{1}+c_{2}}\right) \\
P_{t}^{F}=\frac{c_{1} P_{A}+c_{2} P_{B}}{c_{1}+c_{2}}+\left(1-\theta\left(c_{1}+c_{2}\right)\right)^{t}\left(P_{0}^{F}-\frac{c_{1} P_{A}+c_{2} P_{B}}{c_{1}+c_{2}}\right)
\end{gathered}
$$

Case 2.1 If $\theta\left(c_{1}+c_{2}\right)=2$, that is, $\theta=c_{1}=c_{2}=1$

$$
P_{t}^{F}=\left\{\begin{array}{c}
P^{S}, t=2 k \\
P_{A}+P_{B}-P^{S}, t=2 k+1
\end{array}, k=1,2,3 \ldots\right.
$$

Case 2.2 If $\theta\left(c_{1}+c_{2}\right) \neq 2$

$$
\begin{aligned}
& 1-\theta\left(c_{1}+c_{2}\right) \in(-1,1) \\
& \lim _{\mathrm{t} \rightarrow \infty}\left(1-\theta\left(c_{1}+c_{2}\right)\right)^{t}=0 \\
& P^{F}=\lim _{\mathrm{t} \rightarrow \infty} P_{t}^{F}=\frac{c_{1} P_{A}+c_{2} P_{B}}{c_{1}+c_{2}}
\end{aligned}
$$

Thus, if $\theta \neq 0, c_{1}+c_{2} \neq 0$ and $\theta\left(c_{1}+c_{2}\right) \neq 2$, the final price

$$
P^{F}=\frac{c_{1} P_{A}+c_{2} P_{B}}{c_{1}+c_{2}}=P^{S}+\frac{c_{1}}{c_{1}+c_{2}}\left(P_{A}-P^{S}\right)+\frac{c_{2}}{c_{1}+c_{2}}\left(P_{B}-P^{S}\right)
$$

is only about $c_{1}$ and $c_{1}$ and has nothing to do with $\theta$. In fact, $\theta$ determines the rate at which the price converges to the final price.

Proof of Proposition 2.

Given the following price at every day.

$$
\begin{gathered}
P_{0}^{F}=\mathrm{V}+\frac{H}{2}+\left(w_{1}-w_{2}\right) \frac{H}{2} \\
P_{1, \text { Case } 1.1}^{F}=\frac{V+H+S_{B}}{2}+\left(w_{1}-w_{2}\right) \frac{(V+H)-S_{B}}{2} \\
P_{1, \text { Case } 1.2}^{F}=\frac{V+H+S_{B}}{2}+\left(w_{1}-w_{2}\right) \frac{S_{B}-(V+H)}{2} \\
P_{1, \text { Case } 2}^{F}=\frac{2(V+H)}{3}+w_{1}\left(V+H-\frac{2(V+H)}{3}\right)+w_{2}\left(S_{B}-\frac{2(V+H)}{3}\right) \\
P_{2, \text { Case } 1 A 1}^{F}=\frac{S_{A}+S_{B}}{2}+\left(w_{1}-w_{2}\right) \frac{S_{A}-S_{B}}{2} \\
P_{2, \text { Case } 1 A 2}^{F}=\frac{S_{A}+S_{B}}{2}+\left(w_{1}-w_{2}\right) \frac{S_{B}-S_{A}}{2} \\
P_{2, \text { Case } 1 B}^{F}=\frac{2 S_{B}+H}{3}+w_{2}\left(S_{A}-\frac{2 S_{B}+H}{3}\right)+w_{1}\left(S_{B}-\frac{2 S_{B}+H}{3}\right)
\end{gathered}
$$




$$
\begin{gathered}
P_{2, \text { Case } 2 A}^{F}=\frac{S_{A}}{2}+\frac{V+H}{6}+w_{1}\left(S_{A}-\left(\frac{S_{A}}{2}+\frac{V+H}{6}\right)\right)+w_{2}\left(S_{B}-\left(\frac{S_{A}}{2}+\frac{V+H}{6}\right)\right) \\
P_{2, \text { Case } 2 B}^{F}=\frac{2 S_{A}}{3}+w_{1}\left(S_{A}-\frac{2 S_{A}}{3}\right)+w_{2}\left(S_{B}-\frac{2 S_{A}}{3}\right) \\
P_{2, \text { Case } 2 C}^{F}=\frac{2 S_{A}}{3}+w_{2}\left(S_{A}-\frac{2 S_{A}}{3}\right)+w_{1}\left(S_{B}-\frac{2 S_{A}}{3}\right) \\
P_{2, \text { Case } 2 D 1}^{F}=\frac{S_{A}+S_{B}}{2}+\left(w_{1}-w_{2}\right) \frac{S_{A}-S_{B}}{2} \\
P_{2, \text { Case } D 2}^{F}=\frac{S_{A}+S_{B}}{2}+\left(w_{1}-w_{2}\right) \frac{S_{B}-S_{A}}{2} \\
P_{3}^{F}=\frac{S_{A}+S_{B}}{2}
\end{gathered}
$$

At day 1:

$$
\begin{gathered}
\mathrm{E}\left[R_{1}^{3}\right]=\mathrm{E}\left[R_{1}^{3} \mid S_{B}>V+H\right] \operatorname{Pr}\left(S_{B}>V+H\right)+\mathrm{E}\left[R_{1}^{3} \mid \frac{2}{3}(V+H)<S_{B} \leq V+H\right] \operatorname{Pr}\left(\frac{2}{3}(V+H)<S_{B} \leq V+H\right)+ \\
\mathrm{E}\left[R_{1}^{3} \mid S_{B} \leq \frac{2}{3}(V+H)\right] \operatorname{Pr}\left(S_{B} \leq \frac{2}{3}(V+H)\right)
\end{gathered}
$$

Since $S_{B}$ is uniform on $[0,2 \mathrm{~V}]$

When $\mathrm{H} \leq \mathrm{V}, \mathrm{V}+\mathrm{H} \leq 2 \mathrm{~V}$

$$
\mathrm{E}\left[R_{1}^{3}\right]=\frac{1}{2 V}\left[\int_{V+H}^{2 V}\left(P_{1, \text { Case } 1.1}^{F}-P_{0}^{F}\right)^{3} d y+\int_{\frac{2}{3}(V+H)}^{V+H}\left(P_{1, \text { Case } 1.2}^{F}-P_{0}^{F}\right)^{3} d y+\int_{0}^{\frac{2}{3}(V+H)}\left(P_{1, \text { Case } 2}^{F}-P_{0}^{F}\right)^{3} d y\right]
$$

When $\mathrm{H}>V, V+H>2 V$

$$
\mathrm{E}\left[R_{1}^{3}\right]=\frac{1}{2 V}\left[\int_{\frac{2}{3}(V+H)}^{2 V}\left(P_{1, \text { Case } 1.2}^{F}-P_{0}^{F}\right)^{3} d y+\int_{0}^{\frac{2}{3}(V+H)}\left(P_{1, \text { Case } 2}^{F}-P_{0}^{F}\right)^{3} d y\right]
$$

Define $c_{2}=k_{c} c_{1}$ and $\mathrm{H}=2 k_{H} \mathrm{~V}$. The skewness at day 1 is

$$
S k w_{1}=\mathrm{E}\left[R_{1}^{3}\right]=\left\{\begin{array}{c}
-V^{3}\left(2 k_{H}-1\right)^{2}\left(k_{c}-1\right) \frac{4 k_{H}^{2}\left(3 k_{c}^{2}-3 k_{c}+1\right)+4 k_{H}\left(k_{c}^{2}+k_{c}-1\right)+k_{c}^{2}+k_{c}+1}{8\left(k_{c}+1\right)^{3}}, k_{H} \in[0,0.5) \\
0, k_{H} \in[0.5,1]
\end{array}\right.
$$

At day 2:

When $\mathrm{H} \leq \mathrm{V}, \mathrm{V}+\mathrm{H} \leq 2 \mathrm{~V}$

$\mathrm{EE}\left[R_{2}^{3}\right]=\left[R_{2}^{3} \mid\right.$ Case1.1] $\operatorname{Pr}($ Case1.1 $)+\mathrm{E}\left[R_{2}^{3} \mid\right.$ Case1.2] $\operatorname{Pr}\left(\right.$ Case1.2) $+\mathrm{E}\left[R_{3}^{3} \mid\right.$ Case2 $] \operatorname{Pr}\left(\right.$ Case2) $=\mathrm{E}\left[R_{2}^{3} \mid\right.$ Case1.1] $\frac{V-H}{2 V}+$ $\mathrm{E}\left[R_{2}^{3} \mid\right.$ Case 1.2$] \frac{V+H}{6 V}+\mathrm{E}\left[R_{3}^{3} \mid\right.$ Case2 $] \frac{V+H}{3 V}$ (A.46)

Here

$$
\begin{gathered}
\mathrm{E}\left[R_{2}^{3} \mid \text { Case } 1.1\right]= \\
\frac{1}{2 V-(V+H)} \frac{1}{2 V} \int_{V+H}^{2 V}\left[\int_{y}^{2 V+H}\left(P_{2, \text { Case } 1 A 1}^{F}-P_{1, \text { Case } 1.1}^{F}\right)^{3} d x+\int_{\frac{2 y+H}{3}}^{y}\left(P_{2, \text { Case } 1 A 2}^{F}-P_{1, \text { Case } 1.1}^{F}\right)^{3} d x+\right. \\
\left.\int_{H}^{\frac{2 y+H}{3}}\left(P_{2, \text { Case } 1 B}^{F}-P_{1, \text { Case } 1.1}^{F}\right)^{3} d x\right] d y ; \\
\mathrm{E}\left[R_{2}^{3} \mid \text { Case1.2] }=\frac{1}{V+H-\frac{2}{3}(V+H)} \frac{1}{2 V} \int_{\frac{2}{3}(V+H)}^{V+H}\left[\int_{y}^{2 V+H}\left(P_{2, \text { Case } 1 A 1}^{F}-P_{1, \text { Case } 1.2}^{F}\right)^{3} d x+\int_{\frac{2 y+H}{3}}^{y}\left(P_{2, \text { Case } 1 A 2}^{F}-P_{1, \text { Case } 1.2}\right)^{3} d x+\right.\right. \\
\left.\int_{H}^{\frac{2 y+H}{3}}\left(P_{2, \text { Case } 1 B}^{F}-P_{1, \text { Case } 1.2}^{F}\right)^{3} d x\right] d y ; \\
\mathrm{E}\left[R_{2}^{3} \mid \text { Case } 2\right]=\frac{1}{\frac{2}{3}(V+H)} \frac{1}{2 V} \sum_{i=1}^{3} E_{i} \text { where } \\
E_{1}=\int_{0}^{\frac{2 H}{3}}\left[\int_{V+H}^{2 V+H}\left(P_{2, \text { Case } 2 A}^{F}-P_{1, \text { Case } 2}\right)^{3} d x+\int_{H}^{V+H}\left(P_{2, \text { Case } 2 B}^{F}-P_{1, \text { Case } 2}^{F}\right)^{3} d x\right] d y ;
\end{gathered}
$$




$$
\begin{gathered}
E_{2}=\int_{\frac{2 H}{3}}^{H}\left[\int_{V+H}^{2 V+H}\left(P_{2, \text { Case } 2 A}^{F}-P_{1, \text { Case } 2}^{F}\right)^{3} d x+\int_{\frac{3 y}{2}}^{V+H}\left(P_{2, \text { Case } 2 B}^{F}-P_{1, \text { Case } 2}^{F}\right)^{3} d x+\int_{H}^{\frac{3 y}{2}}\left(P_{2, \text { Case } 2 D 1}^{F}-P_{1, \text { Case } 2}^{F}\right)^{3} d x\right] d y ; \\
E_{3}=\int_{H}^{\frac{2}{3}(V+H)}\left[\int_{V+H}^{2 V+H}\left(P_{2, \text { Case } 2 A}^{F}-P_{1, \text { Case } 2}^{F}\right)^{3} d x+\int_{\frac{3 y}{2}}^{V+H}\left(P_{2, \text { Case } 2 B}^{F}-P_{1, \text { Case } 2}\right)^{3} d x+\int_{y}^{\frac{3 y}{2}}\left(P_{2, \text { Case } 2 D 1}^{F}-P_{1, \text { Case } 2}^{F}\right)^{3} d x+\right. \\
\left.\frac{\int_{2 y+H}^{3 y}}{2}\left(P_{2, \text { Case } 2 D 2}^{F}-P_{1, \text { Case } 2}^{F}\right)^{3} d x+\int_{H}^{\frac{2 y+H}{3}}\left(P_{2, \text { Case } 2 C}^{F}-P_{1, \text { Case } 2}^{F}\right)^{3} d x\right] d y ;
\end{gathered}
$$

When $\mathrm{H}>V, V+H>2 V$

$$
\mathrm{E}\left[R_{2}^{3}\right]=\mathrm{E}\left[R _ { 2 . 2 } ^ { 3 } | \text { Case1.2] } \operatorname { P r } \left(\text { Case1.2) }+\mathrm{E}\left[R_{1}^{3} \mid \text { Case2 }\right] \operatorname{Pr}\left(\text { Case2) }=\mathrm{E}\left[R_{2.2}^{3} \mid \text { Case1.2 }\right] \frac{2 V-H}{3 V}+\mathrm{E}\left[R_{2}^{3} \mid \text { Case2 }\right] \frac{V+H}{3 V}\right.\right.\right.
$$

Here

$$
\begin{aligned}
\mathrm{E}\left[R_{2.2}^{3} \mid \text { Case } 1.2\right]= & \frac{1}{2 V-\frac{2}{3}(V+H)} \frac{1}{2 V} \int_{\frac{2}{3}(V+H)}^{2 V}\left[\int_{y}^{2 V+H}\left(P_{2, \text { Case } 1 A 1}^{F}-P_{1, \text { Case } 1.2}^{F}\right)^{3} d x+\int_{\frac{2 y+H}{3}}^{y}\left(P_{2, \text { Case } 1 A 2}^{F}-P_{1, \text { Case } 1.2}^{F}\right)^{3} d x\right. \\
& \left.+\int_{H}^{\frac{2 y+H}{3}}\left(P_{2, \text { Case } 1 B}^{F}-P_{1, \text { Case } 1.2}^{F}\right)^{3} d x\right] d y
\end{aligned}
$$

Define $c_{2}=k_{c} c_{1}$ and $\mathrm{H}=2 k_{H} \mathrm{~V}$. The skewness at day 2 is

$$
S k w_{2}=E\left[R_{2}^{3}\right]=\left\{\begin{array}{l}
-V^{3}\left(k_{c}-1\right) \frac{8 k_{H}^{5}\left(-3 k_{c}^{2}+3 k_{c}-1\right)+20 k_{H}^{4}\left(2 k_{c}^{2}-k_{c}\right)-20 k_{H}^{3} k_{c}^{2}+k_{c}^{2}+k_{c}+1}{20\left(k_{c}+1\right)^{3}}, k_{H} \in[0,0.5) \\
V^{3}\left(k_{H}-1\right)^{3}\left(k_{c}-1\right) \frac{2 k_{H}^{2}\left(k_{C}^{2}-3 k_{c}+3\right)-k_{H}\left(4 k_{c}^{2}-7 k_{c}+2\right)+2 k_{c}^{2}-k_{c}+1}{5\left(k_{c}+1\right)^{3}}, k_{H} \in[0.5,1]
\end{array}\right.
$$

At day 3:

$$
\begin{gathered}
\mathrm{E}\left[R_{3}^{3}\right]=\mathrm{E}\left[R _ { 3 } ^ { 3 } | \text { Case1.1\&Case1.2] } \operatorname { P r } \left(\text { Case1.1\&Case1.2) }+\mathrm{E}\left[R_{3}^{3} \mid \text { Case2 }\right] \operatorname{Pr}\left(\text { Case2) }=\mathrm{E}\left[R_{3}^{3} \mid \text { Case1.1\&Case1.2] } \frac{2 V-H}{3 V}+\right.\right.\right.\right. \\
\mathrm{E}\left[R_{3}^{3} \mid \text { Case2 }\right] \frac{V+H}{3 V}
\end{gathered}
$$

Here

$\mathrm{E}\left[R_{3}^{3}||\right.$ Case1.1\&Case 1.2] $=\frac{1}{2 V-\frac{2}{3}(V+H)} \frac{1}{2 V} \int_{\frac{2}{3}(V+H)}^{2 V}\left[\int_{y}^{2 V+H}\left(P_{3}^{F}-P_{2, \text { Case } 1 A 1}^{F}\right)^{3} d x+\int_{\frac{2 y+H}{3}}^{y}\left(P_{3}^{F}-P_{2, \text { Case } 1 A 2}^{F}\right)^{3} d x+\int_{H}^{\frac{2 y+H}{3}}\left(P_{3}^{F}-\right.\right.$

$$
\begin{gathered}
\left.\left.P_{2, \text { Case } 1 B}^{F}\right)^{3} d x\right] d y \\
\mathrm{E}\left[R_{3}^{3} \mid \text { Case } 2\right]=\frac{1}{\frac{2}{3}(V+H)} \frac{1}{2 V} \sum_{i=1}^{3} E_{i}
\end{gathered}
$$

where

$$
\begin{gathered}
E_{1}=\int_{0}^{\frac{2 H}{3}}\left[\int_{V+H}^{2 V+H}\left(P_{3}^{F}-P_{2, \text { Case } 2 A}^{F}\right)^{3} d x+\int_{H}^{V+H}\left(P_{3}^{F}-P_{2, \text { Case } 2 B}^{F}\right)^{3} d x\right] d y \\
E_{2}=\int_{\frac{2 H}{3}}^{H}\left[\int_{V+H}^{2 V+H}\left(P_{3}^{F}-P_{2, \text { Case } 2 A}\right)^{3} d x+\int_{\frac{3 y}{2}}^{V+H}\left(P_{3}^{F}-P_{2, \text { Case } 2 B}^{F}\right)^{3} d x+\int_{H}^{\frac{3 y}{2}}\left(P_{3}^{F}-P_{2, \text { Case } 2 D 1}\right)^{3} d x\right] d y ; \\
E_{3}=\int_{H}^{\frac{2}{3}(V+H)}\left[\int_{V+H}^{2 V+H}\left(P_{3}^{F}-P_{2, \text { Case } 2 A}^{F}\right)^{3} d x+\int_{\frac{\int_{y}}{2}}^{V+H}\left(P_{3}^{F}-P_{2, \text { Case } 2 B}^{F}\right)^{3} d x+\int_{y}^{\frac{3 y}{2}}\left(P_{3}^{F}-P_{2, \text { Case } 2 D 1}^{F}\right)^{3} d x+\int_{\frac{2 y+H}{3}}^{\frac{3 y}{2}}\left(P_{3}^{F}-\right.\right. \\
\left.\left.P_{2, \text { Case } 2 D 2}^{F}\right)^{3} d x+\int_{H}^{\frac{2 y+H}{3}}\left(P_{3}^{F}-P_{2, \text { Case } 2 C}^{F}\right)^{3} d x\right] d y ;
\end{gathered}
$$

Define $c_{2}=k_{c} c_{1}$ and $\mathrm{H}=2 k_{H} \mathrm{~V}$. The skewness at day 3 is

$$
\operatorname{Skw}_{3}=V^{3}\left(k_{c}-1\right)^{3} \frac{-k_{H}^{5}+5 k_{H}^{4}+10 k_{H}^{2}+1}{10\left(k_{c}+1\right)^{3}}
$$


It is easy to see that when $k_{c}=1$, we have $S k w_{1}=S k w_{2}=S k w_{3}=0$ and the unconditional skewness over any periods $S k w_{t}^{S}=\frac{\sum_{i=1}^{t} S k w_{i}^{3}}{t}=0$ for $\mathrm{t}=1,2,3$

\section{References}

[1] Jin, Li, and Stewart C. Myers, 2006, R2 around the world: New theory and new tests, Journal of Financial Economics 79, 257-292.

[2] Hutton, Amy P., Alan J. Marcus, and Hassan Tehranian, 2009, Opaque financial report, R2, and crash risk. Journal of Financial Economics 94, 67-86.

[3] Kim, Jeong-Bon, Yinghua Li, and Liandong Zhang, 2011b, CFOs versus CEOs: Equity incentives and crashes, Journal of Financial Economics 101, 713-730.

[4] Kim, Yongtae, Haidan Li, and Siqi Li, 2014, Corporate social responsibility and stock price crash risk, Journal of Banking and Finance 43, 1-13.

[5] Bhargava, Rahul, Sheri Faircloth, and Hongchao Zeng, 2017, Takeover protection and stock price crash risk: evidence from state antitakeover laws, Journal of Business Research 70, 177-184.

[6] Bolton, Patrick, Jose Scheinkman, and Wei Xiong, 2006, Executive compensation and short-termist behaviour in speculative markets, Review of Economic Studies 73, 577-610.

[7] Bebchuk, Lucian A., 2009, Written testimony, hearing on compensation structures and systemic risk, Committee on Financial Services, U.S. House of Representatives, June 11.

[8] Benmelech, Efraim, Eugene Kandel, and Pietro Veronesi, 2010, Stock-based compensation and CEO (dis) incentives, Quarterly Journal of Economics 125, 1769-1820.

[9] Kim, Jeong-Bon, Yinghua Li, and Liandong Zhang, 2011a, Corporate tax avoidance and stock price crash risk: Firm-level analysis, Journal of Financial Economics 100, 639-662.

[10] Kim, Jeong-Bon, Zheng Wang, and Liandong Zhang, 2016, CEO overconfidence and stock price crash risk, Contemporary Accounting Research 33, 1720-1749.

[11] Andreou, Panayiotis C., Christodoulos Louca, and Andreas P. Petrou, 2017, CEO age and stock price crash risk, Review of Finance 21, 1287-1325.

[12] Chen, Joseph, Harrison Hong, and Jeremy C. Stein, 2001, Forecasting crashes: Trading volume, past returns, and conditional skewness in stock prices, Journal of Financial Economics 61, 345-381.

[13] Hong, Harrison, and Jeremy C. Stein, 2003, Differences of opinion, short-sales constraints and market crashes, Review of Financial Studies 16, 487-525.

[14] Chang, Xin, Yangyang Chen, and Leon Zolotoy, 2017, Stock liquidity and stock price crash risk, Journal of Financial and Quantitative Analysis 52, 1605-1637.

[15] Callen, Jeffrey L., and Xiaohua Fang, 2016, Short interest and stock price crash risk, Journal of Banking and Finance 60, 181-194.

[16] Liu, Jinyu and Rui Zhong, 2018, Equity index futures trading and stock price crash risk: evidence from Chinese markets, Journal of Futures Markets 38, 1313-1333.

[17] Bhatia, Mikhail, Viet Nga Cao, Yangyang Chen, and Cameron Truong, 2014, Option trading and stock price crash risk, Working Paper. 